\title{
0 après-coup e a reconsolidação da memória
}

\author{
Graziele Luiza Barizon Scopel Gerbasia,b* , Paulo José da Costa ${ }^{a}$ \\ aUniversidade Estadual de Maringá. Maringá, PR, Brasil \\ 'Prefeitura Municipal de Maringá, Secretaria de Saúde. Maringá, PR, Brasil
}

\begin{abstract}
Resumo: Em diferentes áreas do conhecimento é reconhecido que a memória está sujeita a transformações ao longo do tempo. Partindo desse pressuposto, o objetivo do presente estudo é apresentar uma discussão compreendendo a ideia de que nossas recordações são suscetíveis a transformações e a concepção de après-coup. Há o delineamento de algumas ideias acerca da temporalidade em Psicanálise e do mecanismo de reconsolidação da memória segundo as Neurociências. Utilizando-se tais conceitos, evidenciou-se a viabilidade de se pensar uma interlocução entre a Psicanálise e as Neurociências.

Palavras-chave: après-coup, reconsolidação da memória, psicanálise, neurociências.
\end{abstract}

\section{Introdução}

Em diferentes áreas do conhecimento acerca da mente humana, como na Psicanálise, nas Neurociências e na Psicologia, é reconhecido que a memória não é fidedigna aos fatos reais, estando sujeita a transformações ao longo do tempo, à medida que o sujeito tem novas experiências. As Neurociências cognitivas (originadas de articulações entre Neurobiologia e Psicologia cognitiva) consideram que os registros das experiências, ao serem codificados, armazenados por meio do processo de consolidação e posteriormente evocados, sofrem alterações no seu conteúdo.

Tais alterações são identificadas em pesquisas experimentais que têm como objeto de estudo as bases celulares e moleculares da memória e seus processos cognitivos, demonstrando que esta entra em um estado de labilidade quando evocada e se torna suscetível a acréscimos, subtrações, substituições e distorções ao ser reconsolidada (Alberini, 2005/2011; Alberini, Milekic \& Tronel, 2006; Coccoz, Maldonado \& Delorenzi, 2011; Forcato et al., 2007; Forcato, Rodríguez \& Pedreira, 2011; Forcato, Rodríguez, Pedreira \& Maldonado, 2010; Kroes \& Fernández, 2012; Nadel, Hupbach, Gomez \& Newman-Smith, 2012). Segundo pesquisas neurocientíficas (Agnihotri, Hawkins, Kandel \& Kentros, 2004; Lee et al. 2012), quando há evocação da memória (cuja consolidação requer a formação de novas conexões sinápticas a partir da síntese proteica), as sinapses envolvidas se tornam instáveis e precisam ser estabilizadas novamente por meio da reconsolidação. Portanto, no momento da recordação, a memória adquire maleabilidade e seu conteúdo pode sofrer modificações, ocorrendo algo semelhante a um filme que pode ser reeditado.

Por sua vez, a Psicanálise tem se debruçado sobre tema semelhante, desde Freud até os autores atuais,

*Autor correspondente: grazigerbasi@gmail.com percorrendo um caminho que vai de uma concepção mais arqueológica da memória - em que se buscaria algo como registros soterrados nas profundezas do inconsciente no processo analítico - até noções que privilegiam o mundo interno do sujeito, com maior ênfase na fantasia. Percurso em que ora se ressalta a interpretação, ora a (re)construção das recordações.

A concepção de que os registros mnêmicos estão sujeitos a transformações com o passar do tempo propicia uma interlocução com a noção de après-coup, presente na obra freudiana (Nachträglichkeit, em alemão), e desenvolvida por Jean Laplanche, por vezes traduzida como $a$ posteriori ou, ainda, só-depois, em português (tradução defendida por Maia \& Andrade, 2010). No Vocabulário de Psicanálise, de Laplanche e Pontalis (2000), encontra-se a seguinte definição no verbete a posteriori: "há experiências, impressões, traços mnésicos que são ulteriormente remodelados em função de experiências novas, do acesso a outro grau de desenvolvimento. Pode então ser-lhes conferida, além de um novo sentido, uma eficácia psíquica" (p. 33).

Tendo em vista tais colocações, nosso objetivo é apresentar uma discussão compreendendo a ideia de que nossas recordações são suscetíveis a transformações e a concepção de après-coup, incluindo também comentários sobre a temporalidade em Psicanálise e alguns dados provenientes das Neurociências acerca da reconsolidação da memória, sem aprofundar os seus mecanismos neuromoleculares, pois isso transcenderia nosso propósito.

\section{Nosso ponto de partida}

Quanto à concepção de après-coup, interessa aqui a de J. Laplanche (1999/2006), bem como as obras de outros autores que contribuem para sua compreensão. Sobre estes últimos, em uma busca mais geral em bases de dados on-line pelos termos après-coup, a posteriori e Nachträglichkeit, 
de artigos publicados em língua portuguesa na última década, merecem destaque Abel (2011), André (2008), Bohleber (2007), Maia e Andrade (2010). Como referência no âmbito mundial, de artigos publicados em língua inglesa no International Journal of Psychoanalysis, foram selecionados artigos que versam sobre o après-coup, como Birksted-Breen (2003), Bleichmar (2004), Dahl (2010), Eickhoff (2006), Faimberg (2005), Marion (2012) e Tutté (2004). Também foi considerada a carta aos editores do periódico indicado anteriormente remetida por Bleichmar (2010), que faz referência à reconsolidação da memória.

Por sua expressividade na comunidade científica dedicada às Neurociências e pelo apelo que faz ao diálogo deste campo com a Psicanálise, a memória e os seus mecanismos neurobiológicos de reconsolidação serão elucidados por Eric Kandel (Kandel 2009a/2009b; Lee et al., 2012; Squire \& Kandel, 2003). Esta proposta de interlocução entre Neurociências e Psicanálise dá-se em uma perspectiva de complementaridade, buscando somar esforços para a compreensão de funções psíquicas complexas, tal como explica Bocchi (2012), que será abordada ao longo da discussão.

É importante que se comece um estudo relacionado à memória a partir de uma perspectiva psicanalítica mencionando-se, ainda que de forma breve, como esse tema aparece na obra de Freud. Nesse sentido, Caropreso (2012) desenvolveu um estudo sobre a relação entre memória, percepção e consciência na metapsicologia freudiana. Afirma que Freud pareceu oscilar entre duas concepções diferentes ao longo de sua obra: ora a memória sendo anterior à consciência, ora o contrário. A autora percorreu principalmente as obras Projeto para uma Psicologia científica, as Cartas 39 e 52, o capítulo 7 de $A$ interpretação dos sonhos, incluindo nota adicionada em 1919, "Além do princípio do prazer" e "O eu e o isso". Procedeu, então, a uma divisão da noção freudiana da memória em três fases: a primeira, em que a memória seria anterior à consciência; a segunda, na qual se observa uma oscilação entre os dois modelos, e a terceira, em que a consciência perceptiva seria anterior à memória. Aponta que Freud não chegou a desenvolver as implicações que seu posicionamento mais tardio teria sobre suas demais concepções metapsicológicas.

Assim, estabelecer o que seria uma teoria da memória ou ao menos uma conceituação de memória em Freud se mostra uma tarefa complexa, à qual diversos autores já se dedicaram (Antonello \& Herzog, 2012; Carvalho, 2003; Santos, 2008) e que transcende os objetivos deste trabalho, cujo foco são as alterações dos conteúdos mnêmicos que ocorrem posteriormente a seu registro no aparelho psíquico. Por isso, foi selecionado o Nachträglichkeit, a princípio concebido por Freud, mas que recebeu contribuições de J. Laplanche, que ampliou esse conceito, e também de outros estudiosos. Portanto, o delineamento desse estudo se restringe à concepção de après-coup, deixando-se em suspenso outros mecanismos possivelmente implicados em tais alterações, como as formações do inconsciente, os mecanismos de defesa, as lembranças encobridoras, entre outros.

\section{A noção de après-coup ou a posteriori}

J. Laplanche aborda a noção de après-coup em diversos momentos ao longo de sua obra, notadamente em Problématiques VI: L'après-coup (2006) e no capítulo II, "Notes sur l'après-coup", do livro Entre séduction et inspiration: l'homme (1999). Em ambas as publicações, o autor comenta que a problemática do Nachträglichkeit se configurou por meio de um processo de après-coup, noção que estava dispersa na obra de Freud, e que foi, posteriormente, contemplada com suas próprias contribuições.

Laplanche (2006) apresenta uma discussão sobre as traduções de nachträglich e Nachträglichkeit para outros idiomas, considerando a utilização do primeiro termo como adjetivo e advérbio, e a do segundo como substantivo. Refere-se, então, a três sentidos presentes na obra de Freud, que divide seu estudo em três períodos: textos antes de 1900, um texto de $A$ interpretação dos sonhos e $O$ homem dos lobos. O primeiro sentido seria ulterior, adicionado, secundário, subsequente, "uma consciência que vem depois" (p. 37, tradução nossa). O segundo, em que uma lembrança pode se tornar mais forte do que o evento em si, acontecendo uma retroação, notadamente no aspecto econômico. E o terceiro sentido, no qual Freud mais se aproxima de uma noção de retroação propriamente dita, em que haveria uma inversão da flecha do tempo, onde o sentido de um evento só se daria em um segundo tempo.

Entretanto, opõe-se a concepções que consideram o après-coup de forma demasiadamente mecanicista ou, ainda, reducionista, principalmente quando muito calcadas no desenvolvimento biológico. Também tece críticas a Freud quando, deparado com o insucesso pela busca da cena original, recorre à filogênese. Introduz, então, uma concepção mais dialética, não linear, da temporalidade e, ao mesmo tempo, dirige o foco de seu olhar para a interpessoalidade, considerando as mensagens provenientes do adulto, de seu inconsciente recalcado e, portanto, de sua sexualidade, que demandarão tradução por parte da criança - e, na verdade, futuramente do adulto cujo infantil permanecerá no psiquismo ainda na maturidade.

No arcabouço da Teoria da Sedução Generalizada (TSG) de Laplanche, em que se considera a situação de assimetria entre o adulto - provido do inconsciente recalcado (sexual) - e a criança - com o aparelho psíquico ainda em formação e, a princípio, dotada gradativamente de sua sexualidade polimórfica perversa -, as flechas do tempo parecem também assimétricas, oscilando ora preponderantemente em uma direção, ora em outra, e que podem, além de se inverter, coexistir.

Laplanche (2006) explica porque invoca um modelo tradutivo do après-coup: "E que nenhum processo psíquico, melhor que a tradução, comporta esse duplo movimento indivisível de ser transportado para frente e de se remeter para trás" (p. 169, tradução nossa), considerando a existência de um "traduzir fundamental" da mensagem enigmática do outro. Este autor propõe que o movimento em ambas as direções do après-coup - no sentido progressivo e 
regressivo - ocorre em todos os seres humanos. O primeiro se refere "à mensagem proposta originariamente à criança pelo adulto" (p. 171) e o segundo "se situa nas tentativas de tradução sucessivas do receptor" (p. 171), as quais sempre serão imperfeitas, persistindo algo enigmático.

Em 1999, ele se propôs a expor a noção de Freud do après-coup, discutindo o problema de tradução de nachträglich e Nachträglichkeit e, por fim, apresentar sua própria concepção. Para isso, retomou os três usos desses termos na obra freudiana (o de ulteriormente/mais tarde; o que representa a direção do tempo do passado para o futuro; e aquele que inverte a flecha do tempo: do futuro para o passado). E comenta o seguinte: "Se existir a escolha entre uma concepção determinista que procede do passado para o futuro e uma concepção retrospectiva ou hermenêutica que procede do presente para o passado, Freud escolherá sempre a primeira" (p. 60). Quanto à tradução do substantivo, propõe o termo après-coup, em francês, e afterwardsness, em inglês.

A respeito de sua própria concepção do après-coup, Laplanche (1999) alerta que não se trata de uma escolha entre uma visão determinista ou hermenêutica e tece uma crítica a Freud por considerar os interlocutores nas cenas traumáticas de forma igualitária, ignorando o outro e sua sexualidade, na relação assimétrica que estabelece com a criança. Dessa forma, argumenta que não é "possível considerar o après-coup como uma simples combinação de dois vetores opostos" (p. 65, tradução nossa) e adiciona dois elementos a sua concepção: a mensagem enigmática emitida pelo adulto e o modelo de tradução.

Relembra que, mesmo ao considerarmos a direção temporal retroativa, no sentido de uma reinterpretação do passado, este nunca é factual. "Ele contém antes de uma forma imanente alguma coisa de anterior - uma mensagem do outro" (Laplanche, 1999, p. 65, tradução nossa). E acrescenta que também não se trata apenas de uma posição hermenêutica, em que "cada um interpreta o passado em função de seu presente - porque o passado já tem depositado alguma coisa que demanda ser decifrado que é a mensagem de outra pessoa" (p. 65, tradução e itálicos nossos). Laplanche conclui do seguinte modo:

desde o começo, existe qualquer coisa que vai na direção do passado para o futuro, do outro ao indivíduo em questão, do adulto para o bebê, que eu denomino implantação da mensagem enigmática. Esta mensagem é então retraduzida, seguindo uma direção temporal alternadamente retrógrada e progressiva (de acordo com meu modelo de tradução-destradução-retradução). (p. 66, tradução nossa)

\section{Après-coup e temporalidade em Psicanálise}

A partir deste ponto, serão apresentadas algumas ideias de outros autores que examinaram a noção de après-coup por diferentes vértices, fazendo referência à concepção de J. Laplanche. Um tema que se sobressai na leitura dessas publicações é a noção de tempo ou temporalidade em Psicanálise. Primeiramente, serão considerados alguns dos artigos publicados recentemente em periódicos nacionais.

André (2008), frequentemente citado por outros autores que tratam desta temática (Maia \& Andrade, 2010; Marion, 2012; Menezes, 2009), cujo foco nesse artigo é o après-coup no tratamento analítico, escreve o seguinte sobre a Nachträglichkeit: "põe o tempo de cabeça para baixo, ela condensa em um paradoxo dois movimentos que a lógica exclui: a simultaneidade, a solidariedade, a confusão de um passado-presente e de um presente-passado. $\mathrm{O}$ efeito de après-coup ignora a contradição" (p. 140). E traz uma distinção entre o après-coup e a compulsão à repetição: 0 primeiro, ao repetir, transforma no mesmo ato; a segunda somente repete (p. 141). Propõe também que ele seja compreendido no contexto de uma concepção psicanalítica da temporalidade. "O après-coup confunde nossa representação comum do tempo. Trauma em dois tempos, ele desorganiza a cronologia, não se contentando em invertê-la" (p. 142). Assim, o après-coup condensa duas dimensões: "de um lado, a violência traumática; do outro, a sutileza de uma reinscrição, a complexidade de um significado remodelado" (p. 142).

André (2008) faz críticas a noções de caráter determinista ou hermenêutico, baseadas em concepções lineares do tempo, que consideram o après-coup como mera retrospecção, ressignificação ou reinscrição do passado. Explica que "o après-coup é um trauma, e se não é uma simples repetição é porque contém elementos de significação que dão acesso, desde que encontrem uma escuta e uma interpretação, a uma transformação do passado" (p. 143). Além disso, alerta para que não haja confusão entre a infância (temporal) e o infantil (atemporal), nem entre a sexualidade (primordialmente polimórfica perversa) e genitalidade. $\mathrm{O}$ trauma em dois tempos pode ocorrer em qualquer momento da vida, pois se refere ao infantil de cada um. Outra correlação feita por este autor é do aprèscoup com o recalque:

A associação do recalque com o efeito de aprèscoup propõe uma representação do primeiro menos como fechamento que como transformação, podendo chegar à metamorfose: deformação, condensação, deslocamento, figuração; no encontro com o recalcado, as representações ganham em plasticidade, por mais que esta invente formas que sempre variam no mesmo sentido, ou seja, o da desmedida. Uma plasticidade do recalcado que cria a possibilidade da análise (p. 150).

Este psicanalista ainda enfatiza seu caráter transformador, considerando-o um operador, um agente de passagem da repetição para a rememoração, do caos à história, da infantia à palavra; condensa presente e passado (p. 151). Portanto, 
o fenômeno de après-coup faz fracassar a confrontação binária: verdade histórica ou construção do passado? A "causa" situa-se no T1 [tempo um], no momento do trauma posterior, ou no T2 [tempo 02], quando algo se imprime sem poder ser tratado psiquicamente? O après-coup não responde a essa pergunta, ele a invalida (André, 2008, p. 151, itálicos nossos).

Abordando a transferência no processo analítico, afirma que é no sexual infantil que se pauta o tratamento para gerar transformações, porque confere plasticidade ao psiquismo. Não deixa também de ressaltar a assimetria originária da relação adulto-criança que se reproduz na situação analítica, lembrando que "uma análise nunca ocorrerá entre pessoas que se entendem. Nada é mais distante da ideia da Psicanálise que a ideia da "mutualidade"' (p. 164). E conclui retomando a questão da temporalidade: "o tempo do après-coup não é o tempo que passa, tampouco o 'que não passa'; é o tempo que transforma, que às vezes metamorfoseia” (André, 2008, p. 164). E, por fim, diz: “em Psicanálise, existem apenas verdades provisórias, definitivamente provisórias" (p. 165).

Maia e Andrade (2010) fazem uma análise das concepções de Laplanche (2006) e de André (2009), no mesmo texto mencionado anteriormente, mas na versão publicada na Revue Française de Psychanalyse. Apontam, principalmente, três aspectos convergentes no pensamento desses dois autores: 1) consideram a tensão própria do conceito, que se configuraria a partir da condensação dos dois sentidos da temporalidade (prospecção e retrospecção), daí o trauma em dois tempos e a significação revisitada; 2) a situação de encontro/desencontro entre o adulto e criança; e 3) a solidariedade entre o fenômeno do après-coup e o tratamento psicanalítico, por este viabilizar a rememoração do trauma por meio da transferência e, por este encontro interpessoal potencialmente traumático, mas dotado da escuta analítica, permitir que, transcendendo a repetição, exista abertura para a transformação.

Ainda no artigo desses autores (Maia \& Andrade, 2010), encontra-se uma alusão a duas vertentes controversas nos meios psicanalíticos da atualidade: a daqueles que se orientam "pelo modelo do quebra-cabeça, na busca quase detetivesca de encontrar a cena que falta e que desvelaria o sentido do todo" (p. 87) e a vertente composta por aqueles que, "críticos desse empirismo ingênuo, abandonam-se à atitude fácil de considerar toda a história como um construto atual, visando ressignificar o que, emergindo do inconsciente, resiste ao sentido" (p. 87). Assim, eles alertam a respeito do risco de se fazer uma busca de "causas" por meio de uma "subjetividade ensimesmada" (p. 87), explicando que um mérito do conceito é a conjugação de dois componentes: da realidade de uma situação inter-humana (primeiro tempo) e da força de seu sentido (segundo tempo). Dessa forma, diante do traumático, evita-se tanto uma simples causalidade linear, quanto uma livre hermenêutica.
Por tangenciar esse tema, merece menção a análise realizada por Abel (2011) sobre a relação entre verdade e fantasia em Freud. Abel expõe como a fantasia foi se transmutando de obstáculo à verdade a algo que passa a integrá-la, chegando ao que considera a verdade histórica em Psicanálise: a soma da verdade material (factual) à fantasia do desejo. Verdade histórica que se constitui a posteriori no après-coup? - poder-se-ia questionar. Argumenta que Freud passou "a visar menos a descobrir a verdade material, como arqueólogo, do que a possibilitar a reconstrução ou a construção pelo analisante de sua verdade histórica, como poeta" (p. 58).

Bohleber (2007) traz importante contribuição para esta discussão, parecendo ter uma compreensão de caráter mais hermenêutico da teoria laplancheana. Em seu artigo apresenta o percurso freudiano por uma teoria da memória e seu papel no tratamento; comenta a tendência de correntes psicanalíticas atuais de adotarem abordagens mais narrativas e construtivistas, em detrimento da recordação de acontecimentos históricos, cuja realidade ficaria obscurecida; cita pesquisas neurocientíficas e cognitivistas recentes que fornecem subsídios para a ideia de reconstrução; e, finalmente, chega ao tema das recordações traumáticas. Sobre estas últimas apresenta duas perspectivas: uma que considera que tais lembranças são repetições inalteradas do evento traumático, permanecendo quase que encapsuladas no psiquismo, para alguns se tratando, inclusive, de um tipo diverso de memória, e outra em que estas recordações estariam sujeitas a transformações, já que estariam inseridas na rede associativa do sujeito. O referido autor posiciona-se do seguinte modo:

Assumo, dessa forma, uma posição intermediária entre as visões polarizadas dos pesquisadores empíricos do trauma, que supõem a existência de uma réplica exata do trauma na memória, e das concepções que querem compreender o trauma unicamente dentro dos limites do funcionamento normal geral da realidade psíquica. Nenhuma dessas duas posições me parece sustentável na sua exclusividade (Bohleber, 2007, p. 168).

Este autor sugere, então, que, no processo analítico,

revelar a realidade do trauma e dos seus afetos correspondentes, ou seja, fazer a sua história, por mais fragmentário e aproximado que isso possa ser, é uma condição para esclarecer e compreender a elaboração secundária do trauma e a sua sobreposição por fantasias inconscientes. (Bohleber, 2007, p. 168)

Assim, fantasia e realidade podem ser diferenciadas, à medida que sejam interpretadas e compreendidas no contexto do acontecimento traumático. Alerta que, caso o analista apenas interprete o que ocorre no aqui-agora da situação transferencial da análise em detrimento de uma reconstrução do evento traumático real, sem diferenciar 
fantasia de realidade, corre-se o risco de retraumatizar o paciente.

Portanto, embora esteja sendo posta em discussão a fidedignidade da memória aos fatos reais no campo da neurociência cognitiva, como veremos posteriormente, e isto esteja em consonância com correntes psicanalíticas mais concentradas na realidade psíquica, a clínica do trauma evidencia a necessidade de maior cautela diante de um relativismo e imprecisão entre realidade e fantasia em Psicanálise, entre reconstrução e transformação das recordações do sujeito. É necessária sua historicização, no sentido de uma inserção em um contexto narrativo de seus conteúdos psíquicos por meio do processo tradutivo, retomando aqui as ideias de Laplanche, mas sem se negligenciar os fatos históricos.

Diversos artigos de outros autores contribuem para estas reflexões. Um deles é o de Birksted-Breen (2003), que considera o aqui-agora da análise um paradoxo, uma vez que nunca é um presente puro, por conjugar o tempo prospectivo e o retrospectivo. Argumenta que a temporalidade não linear mais característica da Psicanálise francesa, representada pela ideia do après-coup, e aquela linear, da Psicanálise britânica, segundo um modelo desenvolvimentista, caminham juntas. E menciona os três usos do Nachträglichkeit (correspondentes aos já mencionados no presente texto), mas parece incorrer em certa inexatidão ao afirmar que os desenvolvimentos teóricos que Laplanche faz a partir da obra de Freud correspondem mais à concepção de aprèscoup como um movimento do passado para o futuro, em que "alguma coisa é depositada no indivíduo e que só é reativada mais tarde" (p. 1501, tradução nossa). Na sequência, tem como foco o que seria um terceiro sentido: "alguma coisa é percebida, mas só adquire significado retrospectivamente" (p. 1501, tradução nossa). A autora ainda introduz a ideia de "tempo de reverberação", que define como "o tempo necessário para que elementos perturbadores sejam assimilados, digeridos e transformados" (p. 1506, tradução nossa).

Outros autores demonstraram estar de acordo com a concepção laplancheana ao desenvolverem seus estudos. Entre eles está Faimberg (2005), que considera o aprèscoup importante para uma concepção psicanalítica da temporalidade e o compreende do seguinte modo: "Estabelece uma relação complexa e recíproca entre um evento significativo e sua ressignificação na posterioridade (afterwardsness) por meio da qual o evento adquire nova eficiência psíquica" (p. 1, tradução nossa). Dessa forma, postula que o après-coup é um operador de mudanças no processo de análise: "Na história da transferência, à medida que escutamos o inconsciente, conflitos são ressignificados, lembranças encobridoras podem ser ligadas a diferentes contextos significativos e, na verdade, mesmo memórias podem ser criadas" (p. 5, tradução nossa). Outro exemplo é Eickhoff (2006), para quem "Nachträglichkeit proporciona à memória, não ao evento, o significado traumático e significa uma complementaridade circular nas duas direções do tempo" (p. 1453, tradução nossa) e que, ao final, dialoga com estudos culturais em uma abordagem interdisciplinar.
Por sua vez, Dahl (2010) usa a ideia de uma complementaridade circular ao se referir ao termo Nachträglichkeit. Utiliza o conceito em seus desenvolvimentos teóricos sobre o desenvolvimento da organização ego, abordando, principalmente, a questão da simbolização dos traumas e das ansiedades sem nome. Contudo, este autor afirma que sua tradução por après-coup proposta por Laplanche "é amplamente aceita, apesar de ser explicitamente baseada na concepção inglesa" (p. 96), ou seja, de deferred action. Refere que, para Laplanche, ele "leva a reconstruções de sequências de significados determinados historicamente" (p. 96) e "à busca hermenêutica de significado" (p. 96). Entendimento que parece, ao menos, questionável, pois Laplanche parece ter ido além da noção presente na ideia de deferred action.

Já Marion (2012) se propõe a demonstrar que Nachträglichkeit representa o movimento temporal singular da sessão analítica e o posicionamento característico da mente do analista nessa situação. Esta dimensão de uma temporalidade não linear influenciaria, segundo esta autora, a escuta e a interpretação. Para expor suas ideias, ela discute o tema teoricamente e ilustra suas ideias por meio de casos clínicos. Além disso, apresenta diferentes noções acerca do tempo na obra de Freud: a coexistência de futuro e passado no espaço onírico, a atemporalidade do inconsciente, um movimento "antitempo" (p. 318) no caso da repetição-compulsão (no sentido de uma oposição ao fluxo da vida e de uma insistência repetitiva). Também demonstra como a concepção de Nachträglichkeit aparece na obra freudiana, recorrendo a outros autores de escolas psicanalíticas diferentes, demonstrando certo apreço pela noção de Laplanche, que a explica da seguinte forma:

os autores franceses e especialmente Laplanche (2006) - certamente um dos maiores psicanalistas que "trabalhou" nesse conceito com mais intensidade - se opõem a uma interpretação que reduza o fenômeno a uma ressignificação retrospectiva, já que isso acabaria sendo não apenas reducionista, mas também enganoso. (Marion, 2012, p. 327, tradução nossa)

É importante o destaque dado por Marion (2012) ao período de latência. Uma vez que se concebe um segundo tempo, é preciso considerar o intervalo decorrido entre uma cena e outra, entre um evento e outro: "A latência permanece uma característica do nachträglich que não pode ser deixada de lado; ela não é mais considerada um lapso de tempo em branco, mas um período de profundas reelaborações e transformações no ordenamento psíquico" (p. 321).

Apresentando uma proposta na qual inclui o diálogo com as Neurociências, encontra-se Tutté (2004), que tem como tema o trauma psíquico. Para ele este implica uma "interação contínua e oscilante entre os mundos externo e interno" (p. 898), em que não se pode negligenciar a bagagem individual subjacente à reação do sujeito, 
independentemente do quão violento possa ter sido o evento traumático. Também leva em consideração o trauma em dois tempos e, assim, expõe o conceito de après-coup, segundo Laplanche e Pontalis (1973, citado por Tutté, 2004): $\mathrm{o}$ a posteriori alude a

uma retroação, do presente de volta ao passado, rompendo o tempo cronológico e a causalidade mecânica em favor de um conceito de causalidade dialética e de um modelo do tempo onde passado e futuro são mutuamente condicionados e reciprocamente modulados por seus significados, no ato de estruturação do presente. (p. 900, tradução nossa)

Também em uma perspectiva de contribuição entre a Psicanálise e as Neurociências, Bleichmar (2004) se propõe a examinar alguns dos mecanismos por meio dos quais a interpretação - que é, a princípio, direcionada para a ampliação da consciência - pode promover mudanças no inconsciente. Nesse artigo, o autor recorre a dados provenientes do campo das Neurociências referentes ao mecanismo de reconsolidação da memória, que é de especial interesse aqui, correlacionando-o com a noção de après-coup:

existem diversos experimentos que confirmam a conclusão de que sempre que há recordação ocorre uma reinscrição da memória antiga. Esta reestruturação implica a possibilidade de adicionar elementos que não eram parte da circunstância original. O fenômeno de deferred action (après-coup) descrito por Freud é solidamente corroborado pela pesquisa neurocientífica atual. (pp.1393-1394, tradução nossa)

Alguns anos depois, Bleichmar (2010) menciona a pesquisa neurocientífica que se refere ao uso terapêutico do processo de reconsolidação da memória, no qual esta entra em um estado de labilidade e pode ser totalmente reconstruída, e relembra suas considerações no artigo que publicou em 2004. Finaliza seu texto dizendo o seguinte:

Consideramos indispensável mostrar como a investigação em Psicanálise... está aberta para descobertas da Neurociência e da Psicologia cognitiva e está apta para encontrar aplicações clínicas concretas para elas. $\mathrm{Na}$ verdade, trabalhos atuais sobre a reconsolidação da memória demonstrando que uma nova experiência muda o significado de uma experiência prévia e o integra em sua estrutura, corrobora a concepção freudiana de Nachträglichkeit (deferred action, après-coup). (Bleichmar, 2010, pp. 1525-1526)

\section{Evocação e reconsolidação da memória}

Passemos, então, a estas noções neurocientíficas que parecem poder trabalhar em conjunto com concepções psicanalíticas, em prol de uma maior compreensão das transformações da memória, que ocorrem após sua codificação, armazenamento e evocação.

O neurocientista E. Kandel convida a Psicanálise para uma interlocução (1998/1999) - e foi por este motivo escolhido como referência - com alguns de seus pares, para uma pequena digressão complementar sobre os mecanismos de evocação e reconsolidação da memória, que podem corroborar a ideia de que está sujeita a reedições ao longo do tempo, permitindo um diálogo com a concepção laplancheana de après-coup.

Entretanto é preciso ter clareza acerca do objetivo desse diálogo interdisciplinar. Como ressalta Bocchi (2010), não se trata de "uma junção indiscriminada entre seus domínios. $\mathrm{O}$ encontro entre essas disciplinas não pode ser pensado como uma adequação de uma à outra" (p. 112). E explica que "as especificidades da Psicanálise e das Neurociências . . . não são de antemão excludentes. . . e muito menos se trata de fundi-las em uma disciplina-mãe fundada na biologia, um equívoco frequente na leitura que se faz de Kandel” (pp. 112-113). A proposta dessa autora é a mesma que se pretende neste artigo, ao se incluir dados provenientes das Neurociências: "Trata-se, portanto, de uma busca por uma complementação de esforços para a elucidação de questões sobre as relações mente-corpo-cérebro ... a diversidade de métodos e estratégias conceituais pode ser interessante como um diferencial, e através dela podemos encontrar convergências inesperadas" (p. 113).

A respeito das possíveis transformações da memória, Kandel (2009a) diz que: "a recordação é um processo criativo. Acredita-se que aquilo que a mente armazena é apenas uma porção nuclear da memória. Ao ser recordada, essa porção nuclear é então elaborada e reconstruída, com subtrações, adições, elaborações e distorções" (p. 309). Ao comentar exatamente esta afirmação, relembrando a ideia de Freud expressa em uma de suas cartas a Fliess, Bocchi (2010) aponta que:

Como Freud anuncia na carta 52, a memória é suscetível de rearranjos ao longo do desenvolvimento, uma vez que o psíquico se forma por um processo de "estratificação" e ganha complexidade, na medida em que está sujeito a diferentes registros. Enfim, a concepção freudiana da memória parece ter como modelo a ideia de uma integração progressiva dos processos, enquanto Kandel também concebe a recordação como um processo criativo... (p. 125)

Kandel e Squire (2003) referem que "o cenário mais provável é que novos episódios de armazenamento de informação esculpam de novo, e, continuamente, representações previamente existentes. $\mathrm{O}$ apagamento do velho pelo novo e, provavelmente, a própria passagem do tempo mudam o conteúdo da memória” (p. 89). E acrescentam:

A memória não opera como um gravador ou uma câmera de vídeo, captando, com fidelidade, eventos para uma inspeção posterior. Em vez disso, 
conforme já observado, lembrar envolve a reconstrução de uma trama coerente por meio de fragmentos disponíveis. Quando as pessoas tentam evocar uma memória, por exemplo, algumas vezes incorrem em erros criativos, apagando algumas partes da história, fabricando outras partes e, em geral, tentando reconstruir a informação de modo que faça sentido. Quase sempre a memória funciona pela extração de um significado, não mediante a retenção de um registro literal daquilo que encontramos. (p. 90)

Recorremos novamente à análise empreendida por Bocchi (2010) acerca das convergências entre Freud e Kandel sobre a memória, concluindo que:

a memória é concebida como um dinamismo de forças, cuja ênfase está na relação entre os elementos envolvidos (nunca neles mesmos), e no sentido de que uma função é definida pelos padrões de interação de seus processos ou pelo modo como estes são organizados e reorganizados, e não por uma relação dada de antemão. Podemos deduzir dos dois autores que uma relação direta entre a representação (imagem mnêmica) e o estímulo está totalmente descartada. (p. 125)

Em uma pesquisa recente sobre as sinapses envolvidas na evocação da memória, desenvolvida com colegas (Lee et al., 2012), Kandel parte da hipótese amplamente aceita no meio científico de que a memória entra em um estado de labilidade após a evocação e precisa ser reconsolidada, por processos neuromoleculares nas conexões sinápticas, para então se tornar estável novamente. A mesma ideia já estava presente em trabalho anterior de Kandel (2009b):

a descoberta de que a memória precisa ser mantida ativamente levanta questões relacionadas à evocação e à modificação da memória através da reconsolidação, na qual a recordação de uma experiência aprendida transforma a memória num estado lábil, apenas para se tornar estável novamente com o tempo. (p. 12752, tradução e itálicos nossos)

Dessa forma, evidenciam-se convergências entre Psicanálise e Neurociências acerca da noção de que a memória está sujeita a transformações após seu registro, seja concebendo-se sua inscrição no aparelho psíquico ou seu armazenamento nos sistemas neuronais. Por um lado, existiria uma espécie de transformação por meio do aprèscoup, por outro, a possibilidade quase infinita de reestruturações e reinscrições mediante reconsolidação.

\section{Considerações finais}

Antes de fazer conjecturas sobre possíveis desdobramentos das ideias apresentadas neste texto, é preciso ressaltar que a noção de après-coup aparece em vários momentos na obra de J. Laplanche, os quais não foram contemplados neste artigo de forma a compor uma visão abrangente. Além disso, o próprio autor abordou, em outros textos, os temas da temporalidade, da relação entre determinismo e hermenêutica e entre história e arqueologia em Psicanálise, por exemplo, que mereceriam inclusão nestas reflexões, mas que não caberiam nos limites deste artigo. Contudo, mesmo com tais limitações, é possível tecer algumas considerações finais.

Em primeiro lugar, com base nos estudos examinados ao longo deste artigo, mostrou ser viável pensar as transformações da memória, mediante a ocorrência de novos eventos com o passar do tempo, pela perspectiva de uma interlocução entre Psicanálise e Neurociências, utilizandose, respectivamente, a concepção de après-coup laplancheana e o mecanismo neurobiológico de reconsolidação.

À medida que essas duas concepções acerca do funcionamento da mente/cérebro podem cooperar teoricamente, alguns desdobramentos parecem possíveis e talvez mereçam maior reflexão por parte dos estudiosos. Um deles é o seguinte: uma vez que a reconsolidação da memória tem sido considerada como um fenômeno generalizado e recorrente, é possível que o après-coup também o seja, podendo ter sua compreensão mais ampliada no sentido de compor outros elementos da dinâmica psíquica normal, não estando somente relacionado ao trauma, como é encontrado frequentemente na literatura; embora o trauma, por sua vez, sempre ocorra em dois tempos, no après-coup, como ensina Laplanche.

Outro desdobramento possível é considerar que se o sujeito se constitui por sua história autobiográfica e se a memória é sempre um processo de reconstrução, cada um tende à transformação, o que viabiliza o processo analítico e também as mudanças que ocorrem em função das vicissitudes dessa mesma história, completamente suscetível ao acaso. Esta é, portanto, uma noção que pode contribuir com os estudos acerca da constituição do sujeito vinculada à sua historicidade, indo ao encontro de uma superação de concepções lineares, desenvolvimentistas ou deterministas.

As questões acerca da realidade/verdade (material, histórica, factual etc.) e da fantasia em Psicanálise, ou mesmo as dúvidas sobre as cenas traumáticas estarem ou não sujeitas a alterações, serem ou não permeáveis a outros conteúdos psíquicos, talvez pudessem receber alguma luz a partir desta articulação entre après-coup e reconsolidação. Poderia ganhar força a noção de que, sim, os fatos reais são importantes e devem ser considerados pela clínica psicanalítica, já que são as experiências (dentro ou fora da análise) que podem disparar o processo de transformação. Isto para que, em Psicanálise, evite-se adentrar em um universo mental demasiadamente fantasioso, descolado da realidade factual, ou ainda, diante das comprovações das Neurociências cognitivas acerca da reconsolidação, considerar que tudo o que se recorda é apenas uma construção, uma história repetidamente reeditada, como uma narrativa sempre reescrita em um novo discurso, perdendo as suas bases históricas 
reais. As peças da construção das recordações parecem ser pedaços de realidade factual e de fantasias inconscientes continuamente reconfigurados, rearranjados etc., segundo o tecido mental existente no momento de cada evento, seja ele um fato ou uma reminiscência.

Outro aspecto que pode se somar a essas reflexões é o que seria a tendência a um pensamento não mais em termos binários: realidade ou fantasia, endógeno ou exógeno, determinismo ou hermenêutica, passado $\leftrightarrow$ futuro, mas que se construiria com maior complexidade, seria multifatorial e no qual essas distinções não se sustentariam de forma tão clara. Nem sequer subsistiria uma ideia de tempo com passado, presente e futuro bem delimitados, relegando-se seu papel a um elemento cognitivo que permite certo ordenamento de nossas percepções. Assim, torna-se mais viável uma concepção em que estes três tempos, assim como os movimentos de retrospecção e prospecção, coexistem de certo modo.

Afinal, desde o início do século XX, Einstein revolucionou a concepção científica do tempo com a Teoria da relatividade geral. Construiu a ideia de espaço-tempo, o tecido que ordena o universo composto de matéria/energia, e que também não comporta uma distinção clara entre passado, presente e futuro, os quais seriam ilusões subjetivas. Assim, a peculiaridade da temporalidade em Psicanálise, viabilizada pela noção de après-coup, parece também estar em consonância com a Física contemporânea em sua busca de explicações do universo. Ora, o tempo de nosso universo mental parece ser absolutamente relativo.

\section{The après-coup and reconsolidation of memory}

Abstract: Over time, it is recognized that the memory is subject to changes in different fields of knowledge. Based on this assumption, the objective of this study is to present a discussion comprising the idea that our memories are susceptible to changes and to the conception of après-coup. There is the outline of some ideas about the temporality in psychoanalysis and the memory reconsolidation mechanism according to neurosciences. It was demonstrated the feasibility of considering a dialogue between psychoanalysis and neurosciences, using such concepts.

Keywords: après-coup, memory reconsolidation, psychoanalysis, neurosciences.

\section{L’après-coup et la reconsolidation de la mémoire}

Résumé: Dans les différents domaines de la connaissance est reconnu que la mémoire est susceptible de changer au fil du temps. Sur la base de cette hypothèse, l'objectif de cette étude est de présenter une discussion comprenant l'idée que nos souvenirs sont susceptibles d'évoluer et la conception d'après-coup. Il sont décrivées des idées sur la temporalité en psychanalyse et le mécanisme de reconsolidation de la mémoire selon les neurosciences. L'utilisation de ces concepts démontre la faisabilité de l'examen d'un dialogue entre la Psychanalyse et les Neurosciences.

Mots-clés: après-coup, reconsolidation de la mémoire, Psychanalyse, Neurosciences.

\section{El après-coup y la reconsolidación de la memoria}

Resumen: En diferentes áreas del conocimiento es reconocido que la memoria está sujeta a cambios en el tiempo. Con base en este supuesto, el objetivo del presente estudio es presentar una discusión comprendiendo la idea de que nuestros recuerdos son susceptibles de cambiar y el diseño de après-coup. A partir de eso, hay el delineamiento de algunas ideas acerca de la temporalidad en Psicoanálisis y del mecanismo de reconsolidación de la memoria según las Neurociencias. Se evidenció la viabilidad de considerar un diálogo entre el Psicoanálisis y las Neurociencias, en el uso de tales conceptos.

Palabras clave: après-coup, reconsolidación de la memoria, Psicoanálisis, Neurociencias. 


\section{Referências}

Abel, M. C. (2011). Verdade e fantasia em Freud. Ágora 14 (1), 47-60.

Agnihotri, N. T., Hawkins, R. D., Kandel, E. R., \& Kentros, C. (2004). The long-term stability of new hippocampal place fields requires new protein synthesis. Proceedings of National Academy of Science, 101(10), 3656-3661.

Alberini, C. M. (2005). Mechanisms of memory stabilization: are consolidation and reconsolidation similar or distinct processes? Trends in Neurosciences, 28(1), 51-56.

Alberini, C. M. (2011). The role of reconsolidation and the dynamic process of longterm memory formation and storage. Frontiers in Behavioral Neuroscience, 5, 1-10.

Alberini, C. M., Milekic, M. H. \& Tronel, S. (2006). Mechanisms of memory stabilization and destabilization. Cellular and Molecular Life Sciences, 63, 999-1008.

André, J. (2008). O acontecimento e a temporalidade: o après-coup no tratamento. Ide: Psicanálise e Cultura, 31(47), 139-167.

Antonello, D. F. \& Herzog, R. (2012). A memória na obra freudiana, para além da representação. Arquivos Brasileiros de Psicologia, 64(1), 111-121.

Birksted-Breen, D. (2003). Time and the après-coup. The International Journal of Psychoanalysis, 84, 1501-1515.

Bleichmar, H. (2004). Making conscious the unconscious in order to modify unconscious processing: some mechanisms of therapeutic change. The International Journal of Psychoanalysis, 85, 1379-1400.

Bleichmar, H. (2010). On: Memory in a labile state: therapeutic application. Letter to the Editors. The International Journal of Psychoanalysis, 91, 1524-1526.

Bocchi, J. C. (2010). Freud e Eric Kandel: uma leitura contemporânea da Psicanálise pela neurociência cognitiva a partir do problema da memória. In C. Murta, F. V. Bocca, \& R. T. Simanke (Orgs.), Psicanálise em perspectiva II (cap. 07, pp. 111-129). Curitiba, PR: CRV.

Bohleber, W. (2007). Recordação, trauma e memória coletiva: a luta pela recordação em Psicanálise. Revista Brasileira de Psicanálise, 41(1), 154-175.

Caropreso, F. (2012). A relação entre a memória, a percepção e a consciência na metapsicologia freudiana. In C. Murta, F. V. Bocca, \& R. T. Simanke (Orgs.), Psicanálise em perspectiva III (cap. 03, pp. 99-111). Curitiba, PR: CRV.

Carvalho, P. O. (2003). Uma investigação sobre a memória em Freud. (Dissertação de Mestrado em Psicologia Clínica). Departamento de Psicologia, Pontifícia Universidade Católica do Rio de Janeiro, Rio de Janeiro.

Coccoz, V., Maldonado, H., \& Delorenzi, A. (2011). The enhancement of reconsolidation with a naturalistic mild stressor improves the expression of a declarative memory in humans. Neuroscience, 185, 61-72.

Dahl, G. (2010). The two time vectors of Nachträglichkeit in the development of ego organization: significance of the concept for the symbolization of nameless traumas and anxieties. The International Journal of Psychoanalysis, 91, 727-744.

Eickhoff, F.W. (2006). On Nachträglichkeit: The modernity of an old concept. The International Journal of Psychoanalysis, 87, 1453-69.

Faimberg, H. (2005). Après-coup. The International Journal of Psychoanalysis, 86, 1-6.

Forcato, C., Burgos, V. L., Argibay, P. F., Molina, V. A., Pedreira, M. E., \& Maldonado, H. (2007). Reconsolidation of declarative memory in humans. Learning and Memory, 14, 295-303.

Forcato, C., Rodriguez, M., Pedreira, M. E., \& Maldonado, H. (2010). Reconsolidation in humans opens up declarative memory to the entrance of new information. Neurobiology of Learning and Memory, 93, 77-84.

Forcato, C., Rodriguez, M., \& Pedreira, M. E. (2011). Repeated labilization-reconsolidation processes strengthen declarative memory in humans. PLOS ONE, 6(8), e23305.

Kandel, E. R. (1998). A New Intellectual Framework for Psychiatry. American Journal of Psychiatry, 155(4), 457-469.

Kandel, E. R. (1999). Biology and the Future of Psychoanalysis: A New Intellectual Framework for Psychiatry Revisited. Americam Journal of Psychiatry, 156(4), 505-523.

Kandel, E. R. (2009a). Em busca da memória: o nascimento de uma nova ciência da mente. São Paulo, SP: Companhia das Letras.

Kandel, E. R. (2009b). The biology of memory: a fortyyear perspective. The Journal of Neuroscience, 29(41), 12748-12756.

Kroes, M. C. W. \& Fernández, G. (2012). Dynamic neural systems enable adaptive, flexible memories. Neuroscience and Biobehavioral Reviews, 36, 16461666.

Laplanche, J. (1999). Notes sur l'après-coup. In J. Laplanche, Entre séduction et inspiration : l'homme (cap. II, pp. 5766). Paris: Quadrige/PUF.

Laplanche, J. (2006). Problématiques VI: l'après-coup. Paris: Quadrige/PUF.

Lee, S. H., Kwak, C., Shim, J., Kim, J. E., Choi, S. L., Kim, H. F., ... Kaang, B. K. (2012). A cellular model of memory reconsolidation involves reactivation-induced destabilization and restabilization at the sensorimotor synapse in Aplysia. Proceedings of National Academy of Science, 109(35), 14200-14205.

Maia, L., \& Andrade, F. C. B. (2010). Nachträglichkeit: leituras sobre o tempo na metapsicologia e na clínica. Estudos de Psicanálise, 33, 75-90.

Marion, P. (2012). Some reflections on the unique time of Nachträglichkeit in theory and clinical practice. The International Journal of Psychoanalysis, 93, 317-340.

Menezes, L. C. (2009). Os tempos do après-coup. Ide, 32(49), 165-169. 
Nadel, L., Hupbach, A., Gomez, R., \& Newman-Smith, K. (2012). Memory formation, consolidation and transformation. Neuroscience and Biobehavioral Reviews, 36, 1640-1645.

Santos, L. B. (2008). Sobre a memória em Freud: uma introdução. Língua, literatura e ensino,3, 491-497.
Squire, L. R. \& Kandel, E. R. (2003). Memória: da mente às moléculas. Porto Alegre, RS: Artmed.

Tutté, J. C. (2004). The concept of psychical trauma: a bridge in interdisciplinary space. The International Journal of Psychoanalysis, 85, 897-921.

Recebido: 30/08/2013

Revisado: 27/04/2014

Aceito: 03/10/2014 